\title{
Is the role of trophic control larger in a stressed ecosystem?
}

\author{
F. Jordán
}

Department of Genetics, Eötvös University, Múzeum krt. 4/a, H-1088, Budapest, Hungary.
Phone: +36 1 266-12-96, Fax: +36 1 266-26-94, E-mail: jordanf@falco.geobio.elte.hu

Keywords: Community control, Crystal River, Ecosystem stress, Keystone species, Trophic flow network.

\begin{abstract}
Macroscopic ecosystem studies often complete our knowledge based on population-level experiments and models. In this paper, the changed control of ecosystem functioning is reported by analyzing the structure of the energy flow network of a tidal marsh community (Crystal River, Florida). The positional importance of trophic components is characterized by a graph theoretical approach. Then, positional importance of points is compared to the magnitude of fitting carbon flows (i.e., the importance of links) and the congruency is expressed in percents. These results are presented for both an unperturbed (control) and a thermally stressed creek ecosystem of the river. The comparison of average congruency values for the two communities suggests that, first, trophic control may be stronger in the stressed community and, second, the reliability of carbon flows is also higher in the stressed ecosystem.
\end{abstract}

\section{Introduction}

Food webs, as caricatures in general (Pimm 1982), can be better or worse in approximating reality. The classical collections of binary trophic links (Cohen 1978, Briand 1983) have been developed continuously (e.g., Martinez 1991, Polis 1991, Goldwasser and Roughgarden 1993), following methodical synchronization (Cohen et al. 1993). Differences between both points and edges of food web graphs are investigated, resulting in finer resolution and weighted webs. Web dynamics in space and time is also studied (Warren 1989). Even it is in question whether classical models (e.g., May 1973) having been tested on classical data base (e.g., Cohen 1978) are useful.

As for weighting links, problems were listed earlier (Paine 1980) than the first serious attempts (in the field: Paine 1992). The basis of weighting can be interaction strength (Paine 1980, 1992), impact on stability (de Ruiter et al. 1996) or the magnitude of matter/energy flows (Ulanowicz 1983, 1986). We also have seasonally weighted webs, both with quantitative (Baird and Ulanowicz 1989) and qualitative (Porter 1996, Winemiller 1996) differences between edges. Finally, Ulanowicz (1996) recently presented a weighted web for a stressed ecosystem. After all, we must conclude that there are extremely few usefully weighted webs, thus, at the moment, no statistical analysis is allowed.
However, the analysis of whole trophic flow networks may give insight into the system-level functioning of communities. Thus, even if we only have a few data of good quality, it can be useful (at least, stimulating) to develop models for investigations at the network level. Macroscopic studies may lead us from system-level data to a novel kind of conclusions concerning community function. For example, Ulanowicz (1996) presents a study in which stressful conditions can be inferred from network data (decreasing ascendency indicates stress).

In this paper, I analyse and compare two weighted carbon flow networks described from a thermally stressed and an unperturbed (control) tidal marsh creek ecosystem (used field data were published by Ulanowicz 1996). I calculate the positional importance of trophic components in the network and compare positional importance to the magnitude of carbon flows (importance of links). The congruency of important positions and large fluxes differs in the stressed and the control community. The results suggest that trophic control may be stronger under stress.

\section{Methods and results}

Crystal River bends in Florida, being bordered by tidal marsh gut ecosystems. One of the creeks is heavily 
influenced $\left(\mathrm{T}=+6^{\circ} \mathrm{C}\right)$ by hot water released from a nuclear power station. This thermal stress results in altered community structure (Figures 1 and 2, after Ulanowicz 1996) and dynamics (Part III).

\section{Flow network data}

Species were aggregated into 17 trophic components by Ulanowicz (1983, the names of components are given in the Appendix). Thermal stress does not result in changed species composition but both the pattern of trophic links and their magnitude (expressed in $\mathrm{mg} \mathrm{Cx} \mathrm{m}{ }^{-2}$ $\mathrm{x}_{\text {day }}{ }^{-1}$, Ulanowicz 1996, after an unpublished manuscript of Homer et al.) differ. In the stressed system, one extra link appears (from component \#7 to \#6) and many disappear (e.g., from component \#11 to \#6). Carbon flows are given in Table 1. Flows leading to the same sink component are ranked according to their magnitude. The sign "-" in the column of flows means that there is no such trophic link in the energy flow network, while sign "-." appearing only at ranks means that the consumer (sink) in question is a specialist (or there is no link).

A two-species loop between components \#8 and \#16 was neglected, for it cannot be considered by our model. This simplification does not lead to serious changes in results. This loop appears only as an undirected (horizontal) edge in Figure 1, and the Tables do not contain it. In the stressed ecosystem, cannibalism occurs for species \#11. This simple (one-species) loop was also neglected, for it is out of our interest (cannibalism never affects species deletion models).

In the stressed ecosystem, new top predators occurred (gulf killifish, \#11, and moharra,\#14). Besides changes in trophic links, their importance (as for carbon flows) has also changed, for example, stingray (\#6) gets only 0.01 $\mathrm{mg} \mathrm{Cx} \mathrm{m}{ }^{-2} \mathrm{x} \mathrm{day}^{-1}$ from mullet (\#17), instead of 2.59 . Conversely, benthic invertebrate feeders (\#15) eat more (2.38 $\mathrm{mg} \mathrm{C} \mathrm{x} \mathrm{m}^{-2} \mathrm{x} \mathrm{day}^{-1}$ ) benthic invertebrates (\#5) than before $\left(0.23 \mathrm{mg} \mathrm{C} \mathrm{x} \mathrm{m}^{-2} \mathrm{x} \mathrm{day}^{-1}\right.$, not surprising for they only have this food source in the stressed system).

\section{Positional importance of components}

A class of keystone species (Paine 1969, Mills et al. 1993, Bond 1994, Power et al. 1996) was suggested to comprehend species characterizable by an important position in the trophic network (Jordán et al. 1999). These positional keystones have high keystone indices $(K)$ reflecting both bottom-up and top-down (as well as horizontal) trophically mediated direct and indirect interactions. Further assumptions of the positional keystone model are given elsewhere (Jordán et al. 1999). The positional keystone index predicts key players of the community better whenever trophic control is more important.

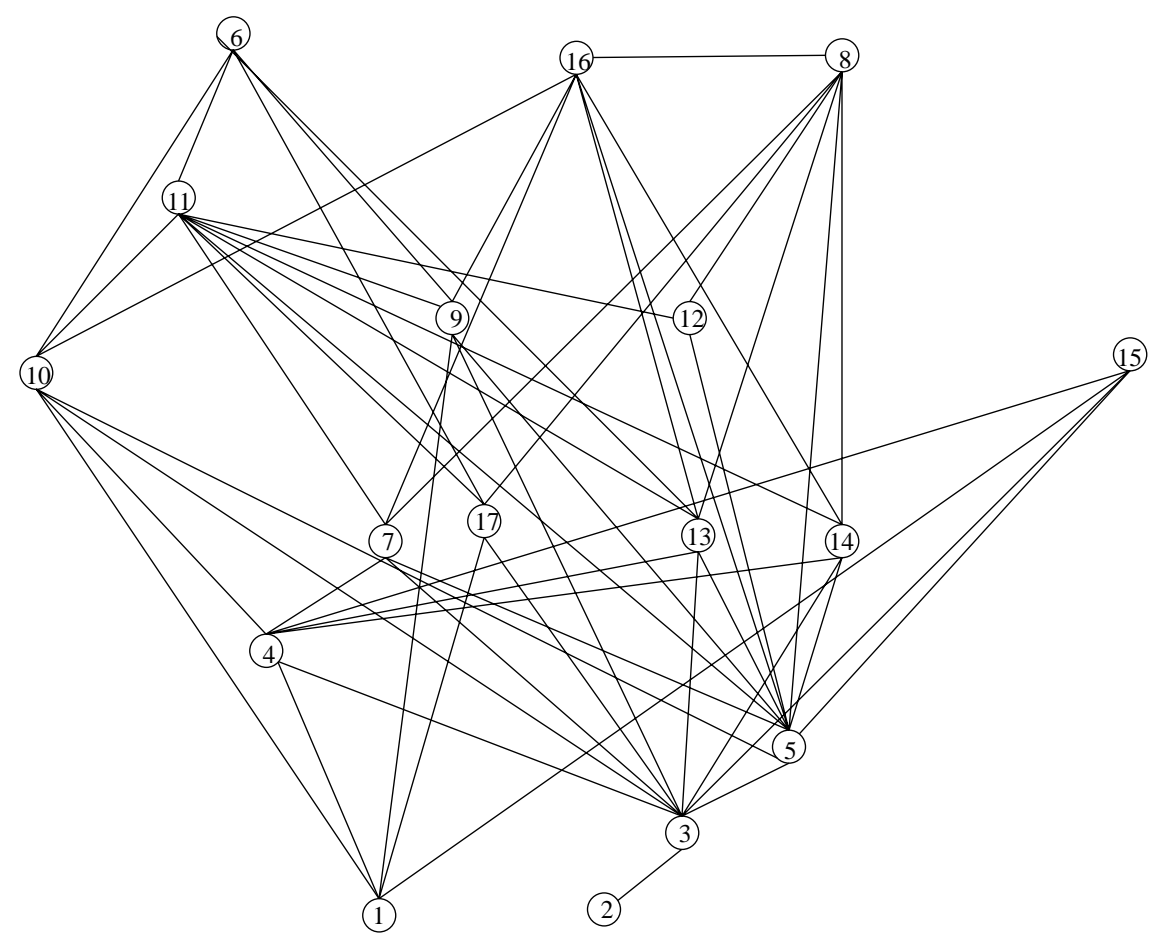

Figure 1. The energy flow network for the 17 major trophic components of the unperturbed Crystal River (Florida) marsh gut ecosystem. Names of components are given in the Appendix. The direction of edges is not shown, the higher one always feeds on the lower one (\#8 and \#16 eat each other). After Ulanowicz (1996). 


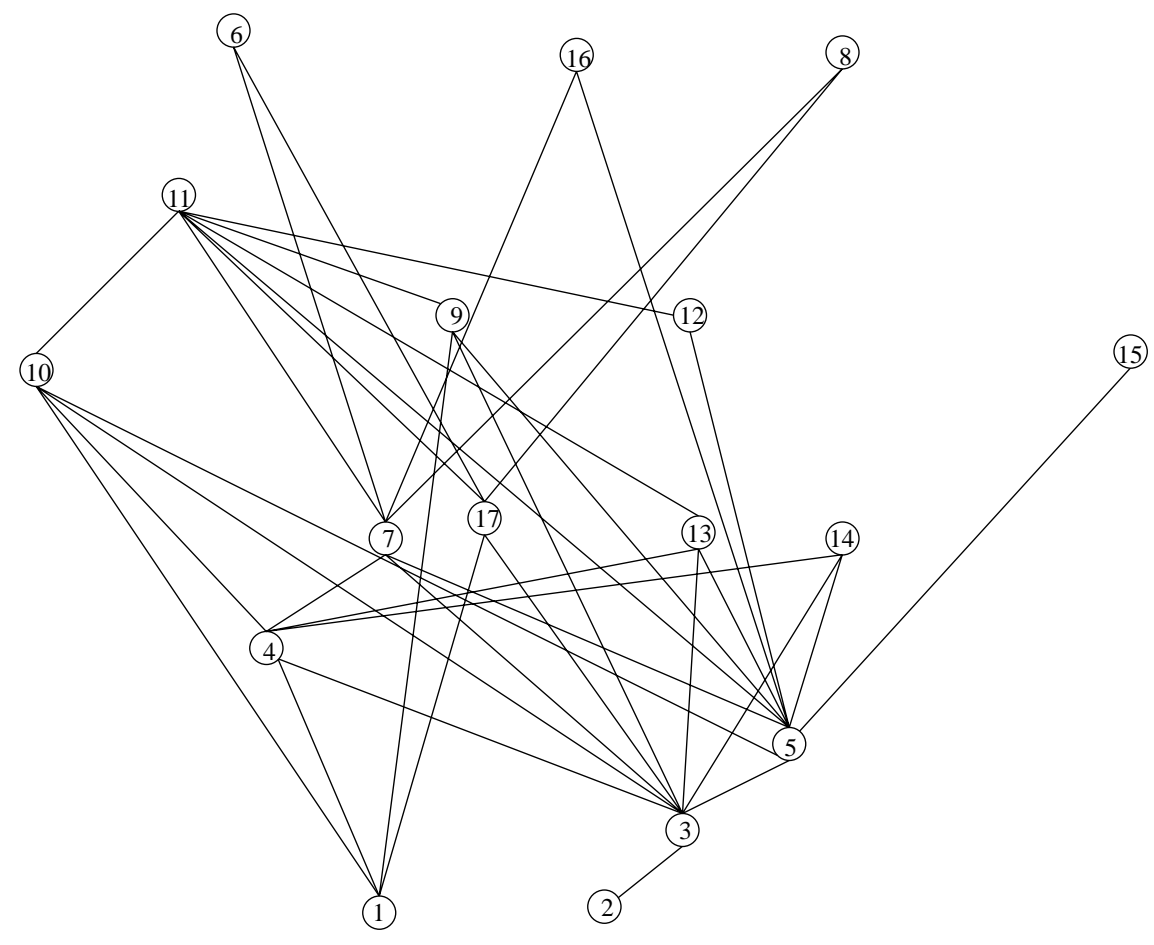

Figure 2. The energy flow network of the Crystal River community in a thermally stressed creek. After Ulanowicz (1996).

Some indirect interactions (e.g., trophic cascade, apparent competition, exploitative competition) are mediated only by trophic links (Ulanowicz and Puccia 1990, Abrams et al. 1996). In principle, our positional keystone model takes into account all of these effects. Others are excluded for they also need nontrophic links (e.g., indirect mutualism, Abrams et al. 1996). If we accept that predation and competition are the major controlling mechanisms in communities, and exploitative and interference competition are roughly equal in importance (Schoener 1983), then we can conclude that the majority of basic interactions are considered by our model. Often, bottom-up energy flows and top-down control effects cannot be separated easily (e.g., feedbacks mediated by indirect and higher order interactions confound the two). Thus, the importance of a network position may mean to be both a main energy gate (Margalef 1968) and mediating large top-down effects. Moreover, predator loss may result in secondary prey extinction. In spite of the problem that different effects are considered the same way, we believe that system-level investigations need some simplification in order to be useful.

Keystone indices measure the importance of positions in energy flow networks in bottom-up $\left(K_{b}\right)$, top-down $\left(K_{t}\right)$ and both directions $(K)$, similarly to the graph theoretical concepts of "status", "contrastatus" and "net status" (Harary 1961). The $K$ keystone index of the $x^{\text {th }}$ species gives the number of species going to secondary extinction, caused by disconnected network flows, following the removal of the $x^{\text {th }}$ species. The bottom-up keystone index $\left(K_{b}\right)$ of the $x$ th species can be calculated as

$\sum_{c=1}^{n} \frac{1}{d c}+\frac{1}{d c} x K b c$

where $n$ is the number of its predators, $d_{c}$ is the number of preys eaten by its $c^{\text {th }}$ predator, and $K_{b c}$ is the bottom-up keystone index of its $c^{\text {th }}$ predator. Thus, $K_{b}$ should be calculated first for higher species in the web (the method needs the exclusion of trophic loops, which is neutral as for results). The top-down keystone index $\left(K_{t}\right)$ can be calculated in the same way, but turning the web upside down. $K$ is the sum of $K_{b}$ and $K_{t}$ (if the relative importance of bottom-up and top-down forces can be estimated, weighting according to $K=a K_{b}+b K_{t}$ is possible, although, this is not easy in practice, see Hunter and Price 1992).

The $K$ indices for each component of both systems are given in Table 2. The average $K$ values for the two webs are also given. All types of $K$ indices are presented for both the control (c) and the stressed (s) community. Since 
Table 1. The list of trophic links between source and sink components, characterized by the magnitude of carbon flows (in $\mathrm{mg} \mathrm{C} \mathrm{x} \mathrm{m}{ }^{-2} \mathrm{x} \mathrm{day}^{-1}$ ) in the control (c) and the stressed (s) ecosystem (data published by Ulanowicz 1996). The energy flows feeding the same consumer (sink) are ranked according to magnitude.

\begin{tabular}{|c|c|c|c|c|c|}
\hline source & sink & flow $_{\mathrm{c}}$ & rank $_{c}$ & flow $_{\mathrm{s}}$ & rank \\
\hline 2 & 3 & 4160 & - & 3160 & - \\
\hline 1 & 4 & 44.7 & 2 & 39.1 & 2 \\
\hline 3 & 4 & 110 & 1 & 117 & 1 \\
\hline 3 & 5 & 2120 & - & 1490 & - \\
\hline 7 & 6 & - & - & 0.04 & 1 \\
\hline 9 & 6 & 0.03 & 4 & - & - \\
\hline 10 & 6 & 0.01 & 5 & - & - \\
\hline 11 & 6 & 0.07 & 3 & - & - \\
\hline 13 & 6 & 0.51 & 2 & - & - \\
\hline 17 & 6 & 2.59 & 1 & 0.01 & 2 \\
\hline 3 & 7 & 0.37 & 3 & 7.74 & 2 \\
\hline 4 & 7 & 0.64 & 2 & 13.6 & 1 \\
\hline 5 & 7 & 1 & 1 & 2.10 & 3 \\
\hline 5 & 8 & 0.12 & 3 & - & - \\
\hline 7 & 8 & 0.65 & 1 & 0.24 & 1 \\
\hline 12 & 8 & 0.05 & 5 & - & - \\
\hline 13 & 8 & 0.64 & 2 & - & - \\
\hline 14 & 8 & 0.06 & 4 & - & - \\
\hline 17 & 8 & 0.03 & 6 & 0.06 & 2 \\
\hline 1 & 9 & 0.44 & 2 & 0.12 & 2 \\
\hline 3 & 9 & 0.79 & 1 & 0.22 & 1 \\
\hline 5 & 9 & 0.15 & 3 & 0.04 & 3 \\
\hline 1 & 10 & 0.32 & 2 & 0.10 & 3 \\
\hline 3 & 10 & 0.71 & 1 & 0.22 & 1 \\
\hline 4 & 10 & 0.22 & 3 & $\begin{array}{l}0.07 \\
\end{array}$ & 4 \\
\hline 5 & 10 & 0.16 & 4 & 0.19 & 2 \\
\hline 5 & 11 & 2.68 & 1 & 1.71 & 1 \\
\hline 7 & 11 & 0.50 & 3 & \begin{tabular}{|l}
0.37 \\
\end{tabular} & 2 \\
\hline 9 & 11 & 0.01 & 8 & \begin{tabular}{|l|}
0.01 \\
\end{tabular} & \begin{tabular}{ll|}
$6-7$ \\
\end{tabular} \\
\hline 10 & 11 & 0.09 & 5 & 0.01 & $6-7$ \\
\hline 12 & 11 & 0.03 & 7 & $\begin{array}{l}0.17 \\
\end{array}$ & 4 \\
\hline 13 & 11 & 2.67 & 2 & 0.33 & 3 \\
\hline 14 & 11 & 0.37 & 4 & - & - \\
\hline 17 & 11 & 0.08 & 6 & 0.06 & 5 \\
\hline 5 & 12 & 5.28 & - & 3.48 & - \\
\hline 3 & 13 & 0.97 & 3 & 0.06 & 3 \\
\hline 4 & 13 & 5.86 & 2 & 0.33 & 2 \\
\hline 5 & 13 & 8.59 & 1 & \begin{tabular}{|l|}
0.49 \\
\end{tabular} & 1 \\
\hline 3 & 14 & 0.90 & 3 & \begin{tabular}{|l|}
0.11 \\
\end{tabular} & 3 \\
\hline 4 & 14 & 3.20 & 1 & 0.40 & 1 \\
\hline 5 & 14 & 2.30 & 2 & 0.28 & 2 \\
\hline 1 & 15 & 0.16 & 2 & - & - \\
\hline 3 & 15 & 0.07 & 4 & - & - \\
\hline 4 & 15 & 0.14 & 3 & - & - \\
\hline 5 & 15 & 0.23 & 1 & 2.38 & - \\
\hline 5 & \begin{tabular}{|l|}
16 \\
\end{tabular} & 0.53 & 3 & $\begin{array}{l}0.09 \\
\end{array}$ & 2 \\
\hline 7 & 16 & 0.74 & 1 & 0.23 & 1 \\
\hline 9 & \begin{tabular}{|l|}
16 \\
\end{tabular} & 0.01 & \begin{tabular}{|l|}
$5-6$ \\
\end{tabular} & - & - \\
\hline 10 & \begin{tabular}{|l|}
16 \\
\end{tabular} & 0.10 & 4 & - & - \\
\hline 13 & \begin{tabular}{|l|}
16 \\
\end{tabular} & 0.56 & 2 & - & - \\
\hline 14 & \begin{tabular}{|l|}
16 \\
\end{tabular} & 0.01 & \begin{tabular}{|l|}
$5-6$ \\
\end{tabular} & - & - \\
\hline 1 & 17 & 8.15 & 2 & 6.08 & 2 \\
\hline 3 & \begin{tabular}{|l|}
17 \\
\end{tabular} & 24.4 & 1 & \begin{tabular}{|l|}
17.2 \\
\end{tabular} & 1 \\
\hline
\end{tabular}


Table 2. The positional keystone index $(K)$ for the trophic components of the control (c) and stressed (s) ecosystem's carbon flow network can be calculated by summing bottom-up (b) and top-down ( $t$ ) positional importance. See text for further details. The last row shows the average positional importance of graph points in both networks.

\begin{tabular}{|l|l|l|l|l|l|l|}
\hline component & $\mathrm{K}_{\mathrm{bc}}$ & $\mathrm{K}_{\mathrm{tc}}$ & $\mathrm{K}_{\mathrm{c}}$ & $\mathrm{K}_{\mathrm{bs}}$ & $\mathrm{K}_{\mathrm{ts}}$ & $\mathrm{K}_{\mathrm{s}}$ \\
\hline 1 & 3.483 & 0 & 3.483 & 3.345 & 0 & 3.345 \\
\hline 2 & 11.517 & 0 & 11.517 & 11.845 & 0 & 11.845 \\
\hline 3 & 10.517 & 1 & 11.517 & 10.845 & 1 & 11.845 \\
\hline 4 & 2.179 & 0.422 & 2.601 & 2.214 & 0.5 & 2.714 \\
\hline 5 & 4.485 & 0.222 & 4.707 & 4.976 & 0.25 & 5.226 \\
\hline 6 & 0 & 6.78 & 6.78 & 0 & 0.941 & 0.941 \\
\hline 7 & 0.483 & 0.629 & 1.112 & 1.429 & 0.764 & 2.193 \\
\hline 8 & 0 & 2.651 & 2.651 & 0 & 0.941 & 0.941 \\
\hline 9 & 0.517 & 0.544 & 1.601 & 0.143 & 0.639 & 0.782 \\
\hline 10 & 0.517 & 0.829 & 1.346 & 0.143 & 1.014 & 1.157 \\
\hline 11 & 0.2 & 3.775 & 3.975 & 0 & 7.635 & 7.635 \\
\hline 12 & 0.317 & 0.122 & 0.439 & 0.143 & 0.139 & 0.282 \\
\hline 13 & 0.683 & 0.629 & 1.312 & 0.143 & 0.764 & 0.907 \\
\hline 14 & 0.483 & 0.629 & 1.112 & 0 & 0.764 & 0.764 \\
\hline 15 & 0 & 0.829 & 0.829 & 0 & 0.139 & 0.139 \\
\hline 16 & 0 & 2.74 & 2.74 & 0 & 0.58 & 0.58 \\
\hline 17 & 0.517 & 0.422 & 0.939 & 1.143 & 0.5 & 1.643 \\
\hline & & average: & 3.451 & & average: & 3.114 \\
\hline
\end{tabular}

the positional keystone indices express importance by the number of secondarily extinct species after a species deletion event, summing $K_{b}$ values of basal species gives the number of nonbasal species. Conversely, summing $K_{t}$ values of top species gives the number of intermediate and basal species (here, possible deviations are due to approximation).

We see that some species become positionally more important, for example, gulf killifish (\#11) due mainly to top-down, and bay anchovy (\#7) due mainly to bottom-up increase in importance. Conversely, stingray (\#6) has lost its power, for its top-down regulatory role has been reduced. The smaller $K$ of silverside (\#13) is due to the decrease of bottom-up positional importance.

\section{Congruency between important positions and large flows}

If both the positional importance of network points and the carbon flows feeding non-specialist consumers are known, we may ask whether large quantities of energy flow through these important points. The congruency between $K$ indices of preys and flows coming from preys was analysed for each non-specialist consumer in both networks (Table 3).

A combinatorial stepwise method is suitable for measuring congruency. A sequence of preys can be compared to the best sequence, where the higher $K(n)$ the larger is the flow from the $n^{\text {th }}$ prey. If the difference between the best and the worst sequence is taken to be $100 \%$, congruency can be expressed in percents. For ex- ample, goldspotted killifish (species \#10) normally eats detritus (\#3) in the largest quantity, then microphytes (\#1), zooplankton (\#4), and benthic invertebrates (\#5). In numbers, the carbon flows (expressed in $\mathrm{mg} \mathrm{Cx} \mathrm{m}{ }^{-2} \mathrm{x}$ day $^{-1}$ ) are $0.71,0.32,0.22$, and 0.16 , respectively (Table 1). The positional keystone indices for the preys are $11.517,3.483,2.601$, and 4.707, respectively (Table 2). The sequence of $K$ values can be adjusted to the sequence of flows in two steps (where one step means the exchange of two neighbours in the rank). The worst sequence (4321) can be stepped to the best one in a minimum of six steps (4321 - 4312 - 4132 - 1432 - 1423 - 1243 - 1234). Thus, the congruency can be determined now as $66.6 \%$ (where 4321 means $0 \%$ and 1234 means 100\% congruency). In the stressed ecosystem, goldspotted killifish prefers benthic invertebrates in second place, thus, its prey choice corresponds to $100 \%$. The congruency values for each non-specialist consumer for both the control and the stressed communities are shown in Table 3 (prey ranking follows energy flows). In the case of similar ranks (e.g., sheepshead killifish, \#9, and moharra, \#14, in the menu of pinfish, \#16, in the control case), the congruency values for the two possible sequences were averaged. For both webs, the average congruency values for all non-specialist consumers are given in the last row of Table 3.

We suggest that a high congruency between important positions and large flows may indicate a greater role for trophic control in community functioning. When main energy gates (mediating large flows) are also in important trophic positions (with mostly dispersive effects; per definitionem, according to our model), trophic interactions 
Table 3. The non-specialist consumers of the control (c) and the stressed (s) ecosystem can be characterized by the congruency (\%) between the positional importance of their preys and the magnitude of energy coming from them. Preys are ranked according to flow magnitude (Table 1). Average congruency values differ between control and stressed conditions.

\begin{tabular}{|c|c|c|c|c|}
\hline consumer & rank of preys (c) & congruency (c) & rank of preys (s) & congruency (s) \\
\hline 4 & $3-1$ & $100 \%$ & $3-1$ & $100 \%$ \\
\hline 6 & $17-13-11-9-10$ & $30 \%$ & $7-17$ & $100 \%$ \\
\hline 7 & $5-4-3$ & $33 \%$ & $4-3-5$ & $33 \%$ \\
\hline 8 & $7-13-5-14-12-17$ & $73 \%$ & $7-17$ & $100 \%$ \\
\hline 9 & $3-1-5$ & $67 \%$ & $3-1-5$ & $67 \%$ \\
\hline 10 & $3-1-4-5$ & $67 \%$ & $3-5-1-4$ & $100 \%$ \\
\hline 11 & $5-13-7-14-10-17-12-9$ & $68 \%$ & $5-7-13-12-17-(9,10)$ & $64 \%$ \\
\hline 13 & $5-4-3$ & $33 \%$ & $5-4-3$ & $33 \%$ \\
\hline 14 & $4-5-3$ & $0 \%$ & $4-5-3$ & $0 \%$ \\
\hline 15 & $5-1-4-3$ & $50 \%$ & - & - \\
\hline 16 & $7-13-5-10-(9,14)$ & $44 \%$ & $7-5$ & $0 \%$ \\
\hline \multirow[t]{2}{*}{17} & $3-1$ & $100 \%$ & $3-1$ & $100 \%$ \\
\hline & average: & $55.4 \%$ & average: & $58.1 \%$ \\
\hline
\end{tabular}

may have larger importance. In this case, large bottom-up energy flows maintain large populations of positional keystones. Large positional keystone populations have strong top-down controlling effects. Thus, high congruency makes strong feedback effects possible in trophic community control.

We already have applied this approach for identifying community control mechanisms in higher and lower regions of food webs (Jordán et al. 1999, testing an idea of Menge and Sutherland 1976) and for analyzing how the relative importance of control mechanisms changes in a community during the four seasons (Jordán 2000, using data published by Baird and Ulanowicz 1989). The analysis of qualitatively weighted webs (Porter 1996, Winemiller 1996) was also attempted but with little success (it is hardly possible to rank trophic links if flow magnitudes are classified into only three or four classes).

\section{Discussion}

The Crystal River marsh gut community is seriously affected by hot water of industrial origin. Even if species composition does not change in the thermally stressed community, the pattern of trophic links (compare Figures 1 and 2) and energy flow magnitudes (Table 1) are altered. Owing to changes in trophic links, the positional importance of species has also changed (Table 2). Finally, the prey preference of consumers can be characterized by a higher congruency between important network positions and large energy (carbon) flows (see, for example, the detailed menu of goldspotted killifish). This suggests that the role of trophic control is larger in the stressed ecosystem (it will be interesting to see how frequently and to what extent congruency increases under stress, having one day a statistically valuable set of network pairs).
Earlier, we have shown that a higher average positional keystone index of trophic components leads to less reliable energy flows through a food web (Jordán and Molnár 1999, Jordán et al. 1999). This means that the food supply of higher consumers is more secure if points in the flow network are of similar importance in trophic position. The average $K$ indices for the control and the stressed ecosystem (Table 2, last row) show that carbon flows are more reliable under stressed conditions (alike the higher redundancy of trophic pathways in communities under stress was also noted before, see Ulanowicz 1984). Since this result depends only on network topology (i.e., it is independent of flow magnitude and congruency), we think that the possibly larger role of trophic control under stress (predicted by changed congruency between important positions and large flows) could be the result of a purely structural property (more homogeneous importance of points) of the flow network.

Given that American data were reevaluated and interpreted in a Hungarian armchair, the author strongly hopes that the identification of trophic components wisely corresponds to functional groups and that flow data were correctly collected. However, many systematic problems of data quality and simplification can become of secondary importance when we focus only on differences between similarly described webs. This analysis needs to be compared with many other similar ecosystems. In the meantime, the results may indicate something valid exclusively for this ecosystem (within our model's limits). Our model also could be developed further at many points, for example, by considering how different is the energy flow from two species ranked as neighbours, or by considering also nitrogen and phosphorous flows (e.g., Ulanowicz and 
Baird 1999). The most useful strategy seems to wait for a wealth of wisely weighted webs.

Acknowledgments: I thank István Molnár and Gábor Vida for many useful discussions. Robert E. Ulanowicz, Tamás Czárán and Árpád Szentesi gave helpful criticism on earlier work. Two anonymous reviewers are also acknowledged for important comments. This study was financially supported by the Hungarian Scientific Research Fund (OTKA) grant no. F029800.

\section{References}

Abrams, P.A., B.A. Menge, G.G. Mittelbach, D.A. Spiller and P. Yodzis. 1996. The role of indirect effects in food webs. In: Polis, G.A. and Winemiller, K.O. (eds.), Food Webs: Integration of Patterns and Dynamics. Chapman and Hall, London. pp. 371395.

Baird, D. and R.E. Ulanowicz. 1989. The seasonal dynamics of the Chesapeake Bay ecosystem. Ecol. Monogr. 59:329-364.

Bond, W.J. 1994. Keystone species. In: Schulze, E.D. and Mooney, H.A. (eds.), Biodiversity and Ecosystem Function. Springer Verlag, Berlin. pp. 237-253.

Briand, F. 1983. Environmental control of food web structure. Ecology 64:253-263.

Cohen, J.E. 1978. Food Webs and Niche Space. Princeton University Press, Princeton

Cohen, J.E., R.A. Beaver, S.H. Cousins, D.L. De Angelis, L. Goldwasser, K.L. Heong, R.D. Holt, A.J. Kohn, J.H. Lawton, N.D. Martinez, R. O'Malley, L.M. Page, B.C. Patten, S.L. Pimm, G.A. Polis, M. Rejmánek, T.W. Schoener, K. Schoenly, W.G. Sprules, J.M. Teal, R.E. Ulanowicz, P.H. Warren, H.M. Wilbur and P. Yodzis. 1993. Improving food webs. Ecology 74:252-258.

De Ruiter, P.C., A.-M. Neutel and J.C. Moore. 1996. Energetics and stability in belowground food webs. In: Polis, G.A. and Winemiller, K.O. (eds.), Food Webs: Integration of Patterns and Dynamics. Chapman and Hall, London. pp. 201-210.

Goldwasser, L. and J. Roughgarden. 1993. Construction and analysis of a large caribbean food web. Ecology 74:1216-1233.

Harary, F. 1961. Who eats whom? Gen. Syst. 6:41-44.

Hunter, M.D. and P.W. Price. 1992. Playing chutes and ladders: heterogeneity and the relative roles of bottom-up and top-down forces in natural communities. Ecology 73:724-732.

Jordán, F. 2000. Seasonal changes in the positional importance of components in the trophic flow network of the Chesapeake Bay. $J$. Marine Syst. (in press).

Jordán, F. and I. Molnár. 1999. Reliable flows and preferred patterns in food webs. Evol. Ecol. Res. 1:591-609.

Jordán, F., A. Takács-Sánta and I. Molnár. 1999. A reliability theoretical quest for keystones. Oikos 86:453-462.

Margalef, R. 1968. Perspectives in Ecological Theory. University of Chicago Press, Chicago.

Martinez, N.D. 1991. Artifacts or attributes? Effects of resolution on the Little Rock Lake food web. Ecol. Monogr. 61:367-392.

May, R.M. 1973. Stability and Complexity in Model Ecosystems. Princeton University Press, Princeton.

Menge, B.A. and J.P. Sutherland. 1976. Species diversity gradients: synthesis of the roles of predation, competition, and temporal heterogeneity. Am. Nat. 110: 351-369.

Mills, L.S., M.L. Soulé and D.F. Doak. 1993. The keystone-species concept in ecology and conservation. BioScience 43:219-224.
Paine, R.T. 1969. A note on trophic complexity and community stability. Am. Nat. 103:91-93.

Paine, R.T. 1980. Food webs: linkage, interaction strength and community infrastructure. J. Anim. Ecol. 49:667-685.

Paine, R.T. 1992. Food-web analysis through field measurement of per capita interaction strength. Nature 355:73-75.

Pimm, S.L. 1982. Food Webs. Chapman and Hall, London.

Polis, G.A. 1991. Complex trophic interactions in deserts: an empirical critique of food web theory. Am. Nat. 138:123-155.

Porter, K.G. 1996. Integrating the microbial loop and the classic food chain into a realistic planktonic food web. In: Polis, G.A. and Winemiller, K.O. (eds.), Food Webs: Integration of Patterns and Dynamics. Chapman and Hall, London. pp. 51-59.

Power, M. E., D. Tilman, J.A. Estes, B.A. Menge, W.J. Bond, L.S. Mills, G. Daily, J.C. Castilla, J. Lubchenco and R.T. Paine. 1996 Challenges in the quest for keystones. BioScience 46:609-620.

Schoener, T.W. 1983. Field experiments on interspecific competition. Am. Nat. 122:240-285.

Ulanowicz, R.E. 1983. Identifying the structure of cycling in ecosystems. Math. Biosci. 65:219-237.

Ulanowicz, R.E. 1984. Community measures of marine food networks and their possible applications. In: Fasham, M.J.R. (ed.), Flows of Energy and Materials in Marine Ecosystems. Plenum Press, London. pp. 23-47.

Ulanowicz, R.E. 1986. Growth and Development: Ecosystems Phenomenology. Springer, Berlin.

Ulanowicz, R.E. 1996. Trophic flow networks as indicators of ecosystem stress. In: Polis, G.A. and Winemiller, K.O. (eds.), Food Webs: Integration of Patterns and Dynamics. Chapman and Hall, London. pp. 358-368.

Ulanowicz, R.E. and C.J. Puccia. 1990. Mixed trophic impacts in ecosystems. Coenoses 5:7-16.

Ulanowicz, R.E. and D. Baird. 1999. Nutrient controls on ecosystem dynamics: the Chesapeake mesohaline community. J. Marine Syst. 19:159-172.

Warren, P.H. 1989. Spatial and temporal variation in the structure of a freshwater food web. Oikos 55:299-311.

Winemiller, K.O. 1996. Factors driving temporal and spatial variation in aquatic floodplain food webs. In: Polis, G.A. and Winemiller, K.O. (eds.), Food Webs: Integration of Patterns and Dynamics. Chapman and Hall, London. pp. 298-312.

\section{Appendix}

Trophic components of the Crystal River (Florida) marsh gut ecosystem carbon flow network (identification by Ulanowicz 1983, after many others):

1. microphytes

2. macrophytes

3. detritus

4. zooplankton

5. benthic invertebrates

6. stingray (Tygon pastinaca)

7. bay anchovy (Engraulis encrasicholus) 

8. needlefish (Syngnathus acus)
13. silverside (Atherinidae)
9. sheepshead killifish (Fundulus confluentus)
14. moharra (Gerreidae)
10. goldspotted killifish (Floridichthys carpio)
15. benthic invertebrate feeders
11. gulf killifish (Fundulus grandis)
16. pinfish (Lagodon rhomboides)
12. longnose killifish (Fundulus similis)
17. mullet (Mugilidae) 